\title{
GMR
}

\section{Correlation analysis of ADAMTS-4, VCAM-1, and TAK1 expression in cartilage tissue from spine tuberculosis}

\author{
Z.X. Qiu, Z.S. Sha, X.M. Che and M.Y. Wang \\ Department of Orthopedics, Qinghai Provincial People's Hospital, Xining City, \\ Qinghai Province, China \\ Corresponding author: M.Y. Wang \\ E-mail: mingyuanwangqwe@sina.com \\ Genet. Mol. Res. 16 (3): gmr16038961 \\ Received July 12, 2016 \\ Accepted January 10, 2017 \\ Published August 17, 2017 \\ DOI http://dx.doi.org/10.4238/gmr16038961 \\ Copyright $(2017$ The Authors. This is an open-access article distributed under the terms of \\ the Creative Commons Attribution ShareAlike (CC BY-SA) 4.0 License.
}

ABSTRACT. A disintegrin and metalloproteinase with thrombospondin
motifs 4 (ADAMTS-4) can effectively degrade articular cartilage matrix
proteoglycan and damage the intervertebral disc of spinal tuberculosis
patients, resulting in deterioration of the physical properties of articular
cartilage. Transforming growth factor $\beta$ activated kinase 1 (TAK1) is
similar to vascular cell adhesion molecule 1 (VCAM-1) and closely
related to a variety of pathophysiological processes. This study intended
to explore the expression of ADAMTS- 4 , VCAM-1, and TAK1 in
cartilage tissue obtained from spinal tuberculosis patients and their
inter-relationships, aiming to provide new treatment approaches for
spinal tuberculosis. Patients with spinal tuberculosis (N $=60$ ) from the
department of orthopedics and patients with traumatic spinal fracture
(N = 60, controls) were recruited for the study. ADAMTS-4, VCAM-
1 , and TAK1 expression was detected by immunohistochemistry.
SPSS 19.0 software was used for data processing and analysis. The
score values of ADAMTS-4, TAK1, and VCAM-1 were $1.45 \pm 0.10$,

Genetics and Molecular Research 16 (3): gmr16038961 
$1.33 \pm 0.09$, and $1.54 \pm 0.11$, respectively, which were significantly higher than those in normal controls $(\mathrm{P}<0.05)$. ADAMTS-4 showed positive correlation with VCAM-1 and TAK1. ADAMTS-4, TAK1, and VCAM-1 expressions increased in spinal tuberculosis patients. They could provide clinical reference for spinal tuberculosis diagnosis and new treatment strategies can be devised by focusing on their positive correlation.

Key words: Spinal tuberculosis; ADAMTS-4; VCAM-1; TAK1; Correlation analysis; Cartilage tissue

\section{INTRODUCTION}

Spinal tuberculosis accounts for most of the cases of bone and joint tuberculosis. Vertebral tuberculosis shows the highest rate of prevalence, whereas adnexa tuberculosis shows the least. The lumbar spine presents the highest mobility in humans and is also the site of the highest incidence of tuberculosis, followed by the thoracic vertebra, cervical vertebra, sacral vertebra, and coccygeal vertebra (Garg and Somvanshi, 2011; Shi et al., 2012). The clinical features of the disease are often complicated with spinal convex deformities and lower limb paraplegia (Rasouli et al., 2012; Zeng et al., 2015). Therefore, clarifying the mechanism of spinal tuberculosis progression is especially significant for the optimization of clinical treatment strategies.

A disintegrin and metalloproteinase with thrombospondin motifs 4 (ADAMTS-4) can effectively degrade cartilage matrix proteoglycan in articular cartilage and damage intervertebral discs in spinal tuberculosis patients, resulting in the deterioration of physical properties of articular cartilage (Wainwright et al., 2013; Yamamoto et al., 2014). Transforming growth factor $\beta$ activated kinase 1 (TAK1) is similar to vascular cell adhesion molecule-1 (VCAM-1) and closely related to various pathophysiological processes. Previous studies have shown that ADAMTS-4, VCAM-1, and TAK1 play vital roles in disease development (Yang et al., 2011; Marchese et al., 2012; Pawlak et al., 2012; Cheng et al., 2015). The present study recruited 60 patients with spinal tuberculosis from the department of orthopedics of Qinghai Provincial People's Hospital from January 2015 to January 2016 to explore ADAMTS-4, VCAM-1, and TAK1 expression in cartilage tissue and their inter-relationship. Patients with traumatic spinal fracture $(\mathrm{N}=60)$ were recruited as controls.

\section{MATERIAL AND METHODS}

\section{Experimental group}

A total of 60 patients with spinal tuberculosis were recruited between January 2015 and January 2016 from the Qinghai Provincial People's Hospital, Xining City Qinghai Province. The inclusion criteria were as follows: 1) patients with spinal tuberculosis receiving surgical treatment, 2) signed informed consent, 3) and who underwent normal preoperative indicator measurements. Patients suffering from spinal tuberculosis in combination with mental illnesses and without the capacity to interact in a socially acceptable manner were excluded. 


\section{Control}

A total of 60 patients with traumatic spinal fracture were recruited, between January 2015 and January 2016, from the Qinghai Provincial People's Hospital. The inclusion criteria were as follows: 1) Patients with traumatic spinal fracture receiving surgical treatment, 2) signed informed consent, 3 ) and who underwent normal preoperative indicator measurements. Patients with traumatic spinal fracture in combination with mental illnesses and without the capacity to interact in a socially acceptable manner were excluded.

No statistical differences were observed based on sex, age, and weight between the two groups $(\mathrm{P}>0.05)($ Table 1$)$.

\section{Table 1. Comparison of general information (means $\pm \mathrm{SD}$ ).}

\begin{tabular}{l|c|c|c|c}
\hline Group & No. of cases & Male/female & Mean age (years) & Mean weight $\left(\mathrm{kg} / \mathrm{m}^{2}\right)$ \\
\hline Control & 60 & $38 / 22$ & $40.27 \pm 15.19$ & $54.67 \pm 3.48$ \\
\hline Experimental group & 60 & $40 / 20$ & $40.36 \pm 14.54$ & $53.58 \pm 3.73$ \\
\hline$t / \chi^{2}$ value & & 0.147 & 0.033 & 1.655 \\
\hline P value & & $>0.05$ & $>0.05$ & $>0.05$ \\
\hline
\end{tabular}

\section{Experimental methods}

\section{Sample collection}

Cartilage tissue samples were surgically obtained and confirmed by pathological examination by two pathologists, independently, for inclusion in the study. The tissue samples were stored at $-80^{\circ} \mathrm{C}$.

\section{Immunohistochemistry and immunofluorescence}

Tissue slices were baked at $60^{\circ} \mathrm{C}$ for $3 \mathrm{~h}$ and soaked in xylene, followed by hydration in alcohol. Next, they were treated with $0.25 \%$ trypsin at $37^{\circ} \mathrm{C}$ for $30 \mathrm{~min}$ for antigen repair. The slices were further washed with $0.01 \mathrm{M}$ phosphate-buffered saline (PBS) and treated with $3 \%$ hydrogen peroxide solution at room temperature $\left(25^{\circ} \mathrm{C}\right)$ for $10 \mathrm{~min}$. After a PBS wash, the slices were treated with $50 \mu \mathrm{L}$ primary antibody (TAK1 (Abcam, Cambridge, MA, USA) 1:300, ADAMTS-4 (Abcam) 1:200, VCAM-1 (Santa Cruz Biotechnology, Dallas, Texas, USA) 1:500) and kept at $4^{\circ} \mathrm{C}$ overnight. They were labeled with biotin and developed by the 3,3-diaminobenzidine substrate. After hematoxylin and eosin staining, the slices were observed under the microscope (CX31-LV320, Olympus, Shinjuku, Tokyo, Japan).

Meanwhile, some slices were used for co-staining to determine the expression of ADAMTS-4, TAK1, and VCAM-1 and analyzed by fluorescent microscopy using fluorescentlabeled secondary antibodies.

\section{Statistical analysis}

Data was analyzed by SPSS 19.0 software. Measured data are reported as means $\pm \mathrm{SD}$ and were compared by the $t$-test. Enumeration data was compared by the chi-square test. Correlation analysis was performed using the Pearson correlation method. $\mathrm{P}<0.05$ was statistically significant. 


\section{RESULTS}

\section{ADAMTS-4, TAK1, and VCAM-1 expression in cartilage tissue}

Qualitative positive cell scoring method was applied for evaluation: 1) 0 points represents the number of positive cells $=0 \%$;2) 1 point refers to the number of positive cells between $0 \sim 25 \%$; 3) 2 points refers to the number of positive cells between $25 \sim 50 \%$; 4) 3 points refers to the number of positive cells between $50 \sim 75 \%$; (5) and 4 points refers to number of positive cells above $75 \%$. Immunohistochemistry results showed that the scores of ADAMTS-4, TAK1, and VCAM-1 in spinal tuberculosis patients were significantly higher than those for the control $(\mathrm{P}<0.05)$ (Table 2 and Figure 1). In addition, co-staining analysis by fluorescent microscopy demonstrated the expression of ADAMTS-4, TAK1, and VCAM-1 in the same cells (Figure 2).

Table 2. ADAMTS-4, TAK1, and VCAM-1 expression in cartilage tissue.

\begin{tabular}{l|c|c|c|c}
\hline Group & Cases & ADAMTS-4 & TAK1 & VCAM-1 \\
\hline Experimental group & 60 & $1.45 \pm 0.10$ & $1.33 \pm 0.09$ & $1.54 \pm 0.11$ \\
\hline Control & 60 & $1.09 \pm 0.07$ & $1.03 \pm 0.10$ & $1.02 \pm 0.09$ \\
\hline$t$ & & 22.845 & 17.273 & 28.340 \\
\hline $\mathrm{P}$ & & $<0.05$ & $<0.05$ & $<0.05$ \\
\hline
\end{tabular}

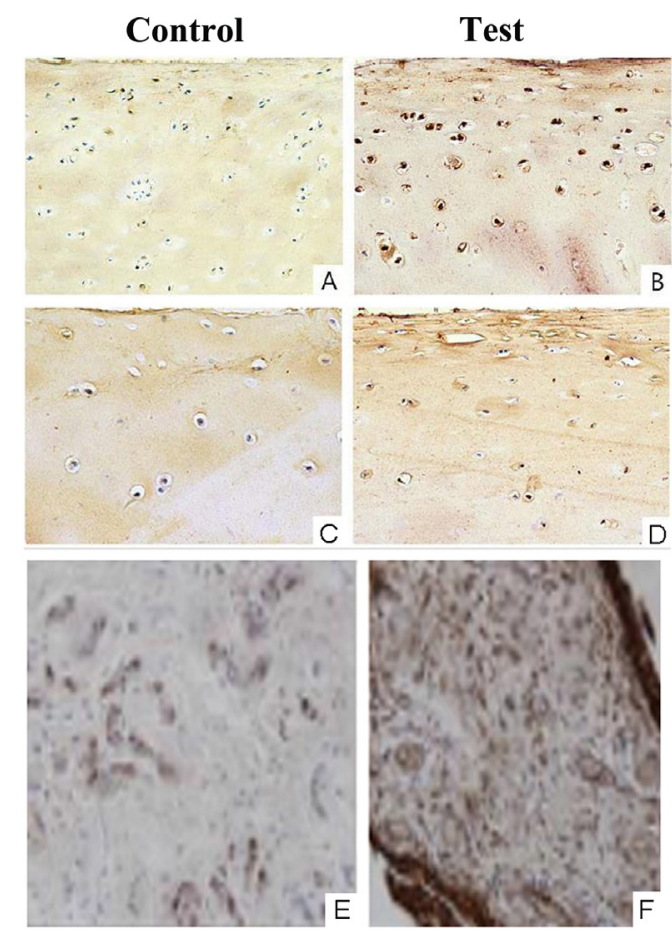

Figure 1. Expression of ADAMTS-4, TAK1, and VACAM-1 in cartilage tissue. The cartilage tissue was surgically obtained followed by immunohistochemical staining for the analysis of the expression of ADAMTS-4 (A-B), TAK1 (C-D), and VCAM-1 (E-F).

Genetics and Molecular Research 16 (3): gmr16038961 


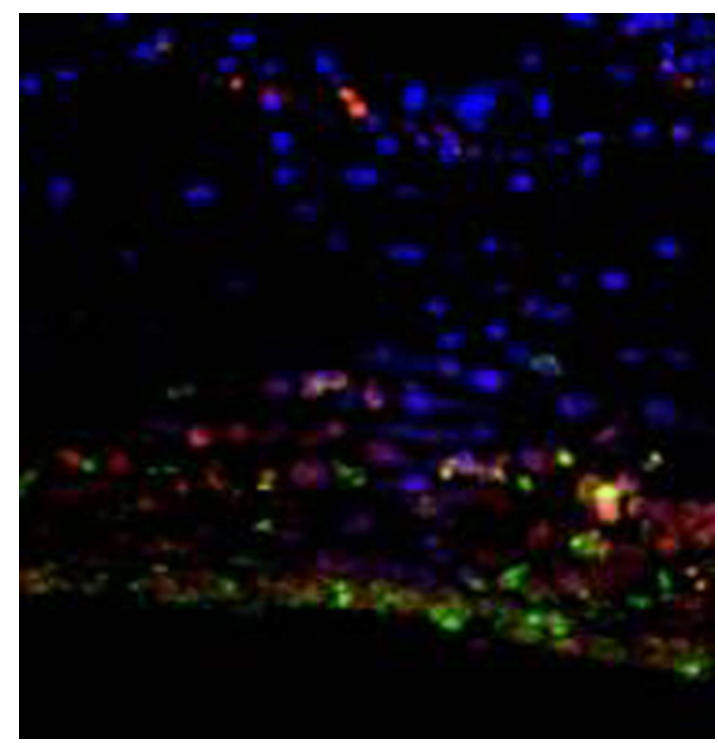

Figure 2. Co-staining for ADAMTS-4, TAK1, and VCAM-1 expression in cartilage tissue. The cartilage tissue slice was baked, oaked in xylene, and hydrated in alcohol for co-staining to determine the expression of ADAMTS-4, TAK1, and VCAM-1, which was analyzed by fluorescent microscopy using fluorescent-labeled secondary antibodies.

\section{Correlation analysis among ADAMTS-4, TAK1, and VCAM-1 expression}

Pearson correlation analysis revealed that ADAMTS-4 was positively correlated with VCAM-1 and TAK1 $(\mathrm{r}>0, \mathrm{P}<0.05)($ Table 3$)$.

Table 3. Correlation analysis of ADAMTS-4, TAK1, and VCAM-1 expression.

\begin{tabular}{l|l|c|c|c}
\hline \multicolumn{2}{c}{} & & VCAM-1 & TAK1 \\
\hline \multirow{5}{*}{ ADAMTS-4 } & Pearson correlation & 1 & 0.758 & 0.958 \\
\cline { 2 - 5 } & Significance (two-tail) & & 0.034 & 0.000 \\
\cline { 2 - 5 } & $\mathrm{N}$ & 60 & 60 & 60 \\
\hline \multirow{5}{*}{ VCAM-1 } & Pearson correlation & 0.0758 & 1 & 0.691 \\
\cline { 2 - 5 } & Significance (two-tail) & 0.034 & 60 & 0.039 \\
\cline { 2 - 5 } & $\mathrm{N}$ & 60 & 0.691 & 60 \\
\hline \multirow{2}{*}{ TAK1 } & Pearson correlation & 0.958 & 0.039 & 6 \\
\cline { 2 - 5 } & Significance (two-tail) & 0.000 & 60 & 60 \\
\cline { 2 - 5 } & $\mathrm{N}$ & 60 & & \\
\hline
\end{tabular}

\section{DISCUSSION}

The main clinical manifestations of spinal tuberculosis include spinal pain, kyphosis, abdominal mass, and spinal nerve compression (Merino et al., 2012; Wang et al., 2012). Currently, there is still a lack of consensus on a single standard mechanism for its pathogenesis. Various factors can induce spinal tuberculosis, such as hereditary predisposition, immune response, inflammatory mediators, and imbalance of the cartilage matrix microenvironment (Li et al., 2012; Rajasekaran, 2012). Spinal tuberculosis progresses through multiple stages 
and involves a variety of cytokines. ADAMTS-4, VCAM-1, and TAK1 play key roles in disease occurrence and development (Jain and Jain, 2012; Tuli, 2013), and their association is an interesting subject for research. Thus, the search for new targets for spinal tuberculosis treatment is exceedingly important.

In-depth quantitative study of the ADAMTS enzyme revealed that the enzyme stored metal ions during the process of purification. The quantitative metal ions were found to be difficult to remove from the enzyme by general methods (Shiomi et al., 2010; Obika et al., 2014). However, chelating agent such as ethylenediaminetetraacetic acid may inactivate the enzyme in the purification process (Matsukawa et al., 2013; Tian et al., 2013). Numerous ADAMTS enzymes have been found to be closely related to spinal tuberculosis, including ADAMTS-1, ADAMTS-4, ADAMTS-5, ADAMTS-8, ADAMTS-9, and ADAMTS-15. Particularly, ADAMTS-4 was considered to have the ability to cause proteoglycan degradation with markedly higher expression levels, compared to those by other enzymes of the same type, in spinal tuberculosis patients (Ren et al., 2013; Roberts et al., 2015).

VCAM is a common type of vascular cell adhesion molecule. The VCAM-1 content in human adipose tissues and microvascular endothelial cells was slightly higher than that in the other parts of the body. However, VCAM-1 expression in cartilage cells needs to be induced by hyaluronic acid and inflammatory cytokines such as IL-1 and TNF- $\alpha$ (Cook-Mills et al., 2011; Tozawa et al., 2011). VCAM-1 content in spinal tuberculosis patients was significantly higher than that in normal controls, and gradually increased with disease progression, indicating the close relationship between VCAM-1 and spinal tuberculosis (Chi et al., 2014). Similar to the VCAM-1 induction process, TAK1 also needs to be activated by the inflammatory cytokines IL-1 and TNF- $\alpha$ (Jung et al., 2012). AP-1 and NF- $\kappa$ B were observed to affect the pathogenic process of spinal tuberculosis (Zheng et al., 2013). However, whether the aberrant expression of VCAM-1 and TAK1 was due to increased secretion of inflammatory cytokines IL-1 or TNF- $\alpha$ in patients with spinal tuberculosis has not been investigated and is the main limitation of the present study.

TAK1 has serine/threonine protein kinase activity (Lin et al., 2015). Many kinds of histopathological processes are closely related to TAK1. TAK1 is located at the branch point of the MAPK and NF- $\mathrm{KB}$ signaling pathways. It can only be activated by IL-1 and TNF- $\alpha$ stimulation (Lim et al., 2012). AP-1 and NF- $\mathrm{KB}$ have significant functions in the occurrence of spinal tuberculosis. After activation, TAK1 could bind to TAB1, triggering the phosphorylation of NF- $\kappa B$ by NIK and IKK and the I $\kappa B$-mediated entrance of NF- $\kappa B$ into the nucleus. TAK1 achieves the purpose of participating in the pathogenesis of spinal tuberculosis (Tai et al., 2014).

The present study included the correlation analysis of ADAMTS-4, VCAM-1, and TAK1 expression. Results revealed that ADAMTS-4, VCAM-1, and TAK1 were positively correlated with each other. Both VCAM-1 and TAK1 need to be activated by inflammatory cytokines, and a reduction in their levels may alleviate the impact of inflammatory cytokines on spinal tuberculosis.

\section{CONCLUSION}

ADAMTS-4, VCAM-1, and TAK1 levels are elevated in spinal tuberculosis and positively correlated with each other. Therefore, these proteins could be considered as new targets for the treatment of spinal tuberculosis. This study could also provide a theoretical basis for the optimization of treatment strategies.

Genetics and Molecular Research 16 (3): gmr16038961 


\section{Conflicts of interest}

The authors declare no conflict of interest.

\section{ACKNOWLEDGMENTS}

We thank the anonymous reviewers for reviewing this manuscript.

\section{REFERENCES}

Cheng Z, Wang J, Zheng Q, Wu Y, et al. (2015). Anterolateral radical debridement and interbody bone grafting combined with transpedicle fixation in the treatment of thoracolumbar spinal tuberculosis. Medicine (Baltimore) 94: e721. http://dx.doi.org/10.1097/MD.0000000000000721

Chi PL, Chuang YC, Chen YW, Lin CC, et al. (2014). The CO donor CORM-2 inhibits LPS-induced vascular cell adhesion molecule-1 expression and leukocyte adhesion in human rheumatoid synovial fibroblasts. Br. J. Pharmacol. 171: 2993-3009. http://dx.doi.org/10.1111/bph.12680

Cook-Mills JM, Marchese ME and Abdala-Valencia H (2011). Vascular cell adhesion molecule-1 expression and signaling during disease: regulation by reactive oxygen species and antioxidants. Antioxid. Redox Signal. 15: 1607-1638. http://dx.doi.org/10.1089/ars.2010.3522

Garg RK and Somvanshi DS (2011). Spinal tuberculosis: a review. J. Spinal Cord Med. 34: 440-454. http://dx.doi.org/10 $.1179 / 2045772311$ Y.0000000023

Jain AK and Jain S (2012). Instrumented stabilization in spinal tuberculosis. Int. Orthop. 36: 285-292. http://dx.doi. org/10.1007/s00264-011-1296-5

Jung J, Ko SH, Yoo do Y, Lee JY, et al. (2012). 5,7-Dihydroxy-3,4,6-trimethoxyflavone inhibits intercellular adhesion molecule 1 and vascular cell adhesion molecule 1 via the Akt and nuclear factor-kappaB-dependent pathway, leading to suppression of adhesion of monocytes and eosinophils to bronchial epithelial cells. Immunology 137: 98-113.

Li L, Zhang Z, Luo F, Xu J, et al. (2012). Management of drug-resistant spinal tuberculosis with a combination of surgery and individualised chemotherapy: a retrospective analysis of thirty-five patients. Int. Orthop. 36: 277-283. http:// dx.doi.org/10.1007/s00264-011-1398-0

Lim ST, Miller NL, Chen XL, Tancioni I, et al. (2012). Nuclear-localized focal adhesion kinase regulates inflammatory VCAM-1 expression. J. Cell Biol. 197: 907-919. http://dx.doi.org/10.1083/jcb.201109067

Lin CC, Pan CS, Wang CY, Liu SW, et al. (2015). Tumor necrosis factor-alpha induces VCAM-1-mediated inflammation via c-Src-dependent transactivation of EGF receptors in human cardiac fibroblasts. J. Biomed. Sci. 22: 53. http:// dx.doi.org/10.1186/s12929-015-0165-8

Marchese ME, Berdnikovs S and Cook-Mills JM (2012). Distinct sites within the vascular cell adhesion molecule-1 (VCAM-1) cytoplasmic domain regulate VCAM-1 activation of calcium fluxes versus Rac1 during leukocyte transendothelial migration. Biochemistry 51: 8235-8246. http://dx.doi.org/10.1021/bi300925r

Matsukawa T, Sakai T, Yonezawa T, Hiraiwa H, et al. (2013). MicroRNA-125b regulates the expression of aggrecanase-1 (ADAMTS-4) in human osteoarthritic chondrocytes. Arthritis Res. Ther. 15: R28. http://dx.doi.org/10.1186/ar4164

Merino P, Candel FJ, Gestoso I, Baos E, et al. (2012). Microbiological diagnosis of spinal tuberculosis. Int. Orthop. 36: 233-238. http://dx.doi.org/10.1007/s00264-011-1461-x

Obika M, Vernon RB, Gooden MD, Braun KR, et al. (2014). ADAMTS-4 and biglycan are expressed at high levels and co-localize to podosomes during endothelial cell tubulogenesis in vitro. J. Histochem. Cytochem. 62: 34-49. http:// dx.doi.org/10.1369/0022155413507727

Pawlak E, Wang L, Johnson PJ, Nuovo G, et al. (2012). Distribution and processing of a disintegrin and metalloproteinase with thrombospondin motifs-4, aggrecan, versican, and hyaluronan in equine digital laminae. Am. J. Vet. Res. 73: 1035-1046. http://dx.doi.org/10.2460/ajvr.73.7.1035

Rajasekaran S (2012). Kyphotic deformity in spinal tuberculosis and its management. Int. Orthop. 36: 359-365. http:// dx.doi.org/10.1007/s00264-011-1469-2

Rasouli MR, Mirkoohi M, Vaccaro AR, Yarandi KK, et al. (2012). Spinal tuberculosis: diagnosis and management. Asian Spine J. 6: 294-308. http://dx.doi.org/10.4184/asj.2012.6.4.294

Ren P, Zhang L, Xu G, Palmero LC, et al. (2013). ADAMTS-1 and ADAMTS-4 levels are elevated in thoracic aortic aneurysms and dissections. Ann. Thorac. Surg. 95: 570-577. http://dx.doi.org/10.1016/j.athoracsur.2012.10.084

Genetics and Molecular Research 16 (3): gmr16038961 
Roberts S, Evans H, Wright K, van Niekerk L, et al. (2015). ADAMTS-4 activity in synovial fluid as a biomarker of inflammation and effusion. Osteoarthritis Cartilage 23: 1622-1626. http://dx.doi.org/10.1016/j.joca.2015.05.006

Shi JD, Wang ZL, Geng GQ and Niu NK (2012). Intervertebral focal surgery for the treatment of non-contiguous multifocal spinal tuberculosis. Int. Orthop. 36: 1423-1427. http://dx.doi.org/10.1007/s00264-011-1478-1

Shiomi T, Lemaître V, D’Armiento J and Okada Y (2010). Matrix metalloproteinases, a disintegrin and metalloproteinases, and a disintegrin and metalloproteinases with thrombospondin motifs in non-neoplastic diseases. Pathol. Int. 60: 477496. http://dx.doi.org/10.1111/j.1440-1827.2010.02547.x

Tai HC, Chang AC, Yu HJ, Huang CY, et al. (2014). Osteoblast-derived WISP-1 increases VCAM-1 expression and enhances prostate cancer metastasis by down-regulating miR-126. Oncotarget 5: 7589-7598. http://dx.doi. org/10.18632/oncotarget.2280

Tian Y, Yuan W, Fujita N, Wang J, et al. (2013). Inflammatory cytokines associated with degenerative disc disease control

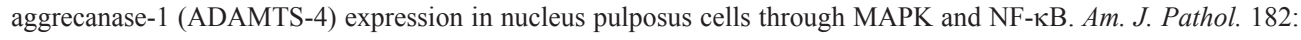
2310-2321. http://dx.doi.org/10.1016/j.ajpath.2013.02.037

Tozawa H, Kanki Y, Suehiro J, Tsutsumi S, et al. (2011). Genome-wide approaches reveal functional interleukin-4inducible STAT6 binding to the vascular cell adhesion molecule 1 promoter. Mol. Cell. Biol. 31: 2196-2209. http:// dx.doi.org/10.1128/MCB.01430-10

Tuli SM (2013). Historical aspects of Pott's disease (spinal tuberculosis) management. Eur. Spine J. 22 (Suppl 4): 529538. http://dx.doi.org/10.1007/s00586-012-2388-7

Wainwright SD, Bondeson J, Caterson B and Hughes CE (2013). ADAMTS-4_v1 is a splice variant of ADAMTS-4 that is expressed as a protein in human synovium and cleaves aggrecan at the interglobular domain. Arthritis Rheum. 65: 2866-2875. http://dx.doi.org/10.1002/art.38102

Wang H, Li C, Wang J, Zhang Z, et al. (2012). Characteristics of patients with spinal tuberculosis: seven-year experience of a teaching hospital in Southwest China. Int. Orthop. 36: 1429-1434. http://dx.doi.org/10.1007/s00264-012-1511-z

Yamamoto K, Owen K, Parker AE, Scilabra SD, et al. (2014). Low density lipoprotein receptor-related protein 1 (LRP1)mediated endocytic clearance of a disintegrin and metalloproteinase with thrombospondin motifs-4 (ADAMTS-4): functional differences of non-catalytic domains of ADAMTS-4 and ADAMTS-5 in LRP1 binding. J. Biol. Chem. 289: 6462-6474. http://dx.doi.org/10.1074/jbc.M113.545376

Yang Y, Xia F, Hermance N, Mabb A, et al. (2011). A cytosolic ATM/NEMO/RIP1 complex recruits TAK1 to mediate the NF-kappaB and p38 mitogen-activated protein kinase (MAPK)/MAPK-activated protein 2 responses to DNA damage. Mol. Cell. Biol. 31: 2774-2786. http://dx.doi.org/10.1128/MCB.01139-10

Zeng H, Zhang Y, Shen X, Luo C, et al. (2015). Staged treatment of thoracic and lumbar spinal tuberculosis with flow injection abscess. Int. J. Clin. Exp. Med. 8: 18383-18390.

Zheng Y, Yang W, Aldape K, He J, et al. (2013). Epidermal growth factor (EGF)-enhanced vascular cell adhesion molecule-1 (VCAM-1) expression promotes macrophage and glioblastoma cell interaction and tumor cell invasion. J. Biol. Chem. 288: 31488-31495. http://dx.doi.org/10.1074/jbc.M113.499020

Genetics and Molecular Research 16 (3): gmr16038961 